\title{
Supporting Learning: An Examination of Two Teacher Development Collectives
}

\author{
XAVIER FAZIO \& TIFFANY L. GALLAGHER \\ Brock University (Canada)
}

\begin{abstract}
This study examined two teacher development cases (middle/secondary school science teachers and elementary learning resource teachers) from which significant professional learning outcomes emerged. Both collectives exhibited characteristic qualities ascribed to complexity theory (e.g., selforganized; bottom-up emergent; ambiguously bounded). This post hoc analysis provides evidence of the robustness of complexity theory and its applicability to analyzing professional development collectives. A diagrammatic representation is provided as a tool for the development and study of teacher development collectives. Recommendations are offered to researchers and teacher development facilitators to use complexity theory at the outset of their projects.
\end{abstract}

\section{Introduction}

Professional development as a term and as a strategy has run its course. The future of improvement, indeed of the profession itself, depends on a radical shift in how we conceive learning and the conditions under which teachers and students work (Fullan, 2007, p.35).

Educational reforms aimed at changing the processes and products of teaching and learning in schools necessarily require teachers to develop new understandings and skills. But what characteristics and principles best inform how to design teacher development experiences? Fundamental first steps generally include deciding on the goal of the teacher learning experiences then creating a context for the participants' experience, followed by implementing and assessing the progress of the teachers. 
However, this heuristic on the surface is misleadingly linear and deceptively simple. The reality is that the collective interactions of teachers, contextual elements, and knowledge found within these teacher development collectives that exhibit successful outcomes, behave in non-linear and unpredictable ways which can impact teachers' practice. Using linear or reductionist principles fails to capture the inherent complexity of effective teacher development learning phenomenon. A novel way forward is to design productive teacher development experiences that can promote learning premised on principles of complexity theory. Educators have recently begun to use the ideas of complexity to inform teaching practice and educational research (see: Davis, Sumara, \& Luce-Kapler, 2008). Our positioning of complexity theory in this paper is as a container of sorts to analyze the collectives' emergence and sustainability embodied through what Davis (2004) refers to as "complexivist discourse." Our intention in this paper is a modest one: to broaden the purview of teacher development in order to stimulate ideas on what could be, and what is doable, within the real world context of teacher development.

This paper presents a post-hoc examination of two teacher development cases from which significant professional learning outcomes emerged. On the surface, these two cases (middle and secondary school science teachers; elementary resource teachers) appear to be disparate, but in fact as the teacher collectives progressed they both began to exhibit characteristic qualities ascribed to complexity theory.

We first present an analysis of the two teacher development collectives' characteristics and map these qualities onto a complexity framework in order to provide empirical substantiation between complexity theory and the collectives. Finally, we will propose a diagrammatic representation based on complexity theory which can be applied by facilitators of teacher development and practitioners in their local educational milieu.

\section{Theoretical Perspectives}

\section{Overview of Complexity Theory}

In order to describe what is meant by a complex system, we contrast this construct with what is not a complex or a simple system ${ }^{1}$. Succinctly, a system is a unit of related elements that act together in an integrated manner. As explained by Davis and Simmt (2003), “...for a simple system, actions and interactions of each part can be characterized in detail and the behaviour of the systems can be predicted with great precision" ( $p$. 139). These types of systems do not have the capacity to learn and are predictable using reductionist techniques, which are consistent with linear, mechanistic and direct methodologies (Doll, 1993). Complex systems, in contrast, can learn and are not readily analyzed using reductionist methods. In particular, complex systems (or "complex unities" or "complex phenomena") are adaptive, emergent, and self-maintaining entities

\footnotetext{
${ }^{1}$ For a detailed explanation regarding differences between simple, complicated, and complex systems, see Davis and Simmt (2003).
} 
that maintain their coherence across time (Davis et al., 2008). In essence, complex social systems arise from a diverse group of agents (i.e., humans) following rules or internal models, aggregated together and exchanging resources and ideas, and emerging as a form of collective behaviour which is unanticipated (Holland, 1995; Paley, 2007).

With roots in science and mathematics, complexity theory is a relatively young yet evolving area of knowledge and inquiry. The hallmark characteristic of this theory is its interdisciplinary breadth which cuts across traditional disciplinary boundaries and, subsequently, develops new discourses in the arts, sciences, and social sciences (Davis \& Sumara, 2006). Educators have recently begun to use the theories and ideas of complexity to inform teaching and research practice (Davis \& Simmt, 2003; Davis \& Sumara, 2006; Phelps, 2005; Volk \& Bloom, 2007). Without question, the recent evolution of journals and associations dedicated to complexity ideas (e.g. Complicity: $A n$ International Journal of Complexity and Education; Chaos \& Complexity Theories - Special Interest Group of the American Educational Research Association) gives support to its emergence as a viable scholarly field in education.

To analyze the characteristics that support learning within teacher development collectives, it is important to elaborate on the qualities of a complex system versus a noncomplex system. Davis and Sumara (2006) have synthesized and developed a comprehensive list of complex system qualities:

Self-organized

Bottom-up emergent

Short-range relationships

Nested structures

Ambiguously bounded

Organizationally closed

Structure determined

Far-from equilibrium

This list provides a suitable framework to analyze the educational phenomena addressed in this study. Despite the range of qualities that are captured under the hospices of complexity, certain necessary but insufficient conditions must be met in order for the emergence and sustainability of complex systems. These include for example: internal diversity and redundancy, decentralized control, and neighbour interactions (Davis \& Sumara, 2006). While these conditions were evident in each of the teacher development collectives, we chose to focus on specific qualities that best reflected our precedent position as facilitators and researchers within our respective collectives. This analytical stance poised us to be better able to explore the qualities of the collectives (i.e., structures and processes) for the individual teachers and the collective as a whole, using a post hoc analysis. The qualities chosen for this study were: self-organized, bottom-up emergent, and ambiguously bounded. 
We will briefly explain these three germane qualities of complex systems which were apparent within the teacher development collectives from our study. Selforganized which is perhaps the sine qua non quality of complex systems, is the manner in which a collective "bootstraps" itself. The well-known saying, "the whole is greater than the sum of its parts" helps to summarize this quality. As Davis and Sumara (2006) explain, "self-organization is also known as emergence...agents that need not have much in common can join into collectives that seem to have clear purposes" (p. 18). Accordingly, bottom-up emergence is related to self-organization. Bottom-up emergence identifies the lack of central control of the emergent phenomena. More importantly, the intelligent outcomes from a collective arise from the interdependent relations amongst the diverse individuals. This paradoxical phenomenon emphasizes the "...independent actions of individual agents who act out of self-interest and who may even be motivated by profound selfishness" (Davis \& Sumara, 2006, p. 85). Said differently, there is no specific pre-determined outcomes for all the individual participants and the collective (Davis et al., 2008). The participants (i.e., agents) act synergistically at a micro-level, and display an emergence at the macro-level, fuelled by a dynamical relationship between the agents and a collective as whole (Bar-Yam, 2004). Finally, ambiguously bounded is a quality that appears to be an oxymoron, yet it accurately specifies this dynamic quality of a complex collective. Specifically, ambiguously bounded systems exchange matter and/or information with their contexts, and are embedded within other complex systems in intricate networks. These characteristics, unfortunately, make identifying the boundaries of these collectives difficult to research especially when trying to separate them apart from other complex systems, as pointed out by Davis and Sumara (2006): "Not only can it be difficult to distinguish one system from another, or one level from another, systems can unfold within one another" (p. 97). Nevertheless, complexity theory demands simultaneous consideration of elements found within teacher development systems (i.e., teachers), the relationships amongst these elements (e.g., facilitation, discussions), and the social context (e.g., schools) embedding these elements.

\section{Teacher Development Designs}

What we refer to as "teacher development" in this paper is based on Bell and Gilbert's (1996) model of teacher development which encompasses three essential components: social, personal, and professional development. Social development involves the renegotiation and reconstruction of teaching practices while collaborating with other teachers on a common inquiry focus. Personal development involves each teacher constructing, evaluating, and accepting (or rejecting) newly constructed knowledge, and beliefs. Professional development involves not only the use of teaching activities in the classroom but also the development of the beliefs and knowledge underlying the practice. When these three elements of teacher development act together, they create a self-organized system of interdependent teachers; that is, a complex teacher development collective, where learning can occur.

Teacher development can be succinctly described as teachers acquiring or adapting

new knowledge, beliefs, and skills in order to change their educational practices. The 
most common teacher development methods used are transmission-type models: teachers attend one-day workshops or presentations, de-contextualized from the educational milieu of their practices. These can include, but are not limited to, workshops, professional institutes, and seminars. However, there tends to be a tacit assumption that teachers will adopt and implement all ideas presented in these one-off sessions. This linear and mechanistic teacher development model is generally ineffective in promoting transformative teacher development (Loucks-Horsley, Love, Stiles, Mundry, \& Hewson, 2003), necessary for changing beliefs and adopting complex knowledge schemata and skill sets. Other teacher development designs such as: action research, collaborative curriculum development and implementation, study groups which examine student work, and immersion in an instructional experience that is to be developed for students, provide a better opportunity to not only develop awareness, but translate teachers' new learning into practice. Teacher development designs such as these, when examined through a complexity theoretical framework, better support longterm and non-linear processes of teacher learning (see: Hoban, 2002; Yoon \& Klopfer, 2006). This, can lead to substantive teacher learning and positive changes in professional practice.

Our rationale for this post-hoc analysis was to determine the robustness of complexity theory qualities and link them to the structures and functions found within two teacher development collectives. We acknowledge that the collectives can also be analyzed through constructivist and constructionist theories (e.g., situated learning theory, social constructivist theory). These theoretical frames can also provide important insights into teacher development. However, we elected to use complexity theory, as we agree with Davis and Sumara (2006) in that complexity thinking provides a unique transdisciplinary line of discourse that can move our thinking forward within this domain. The following research questions delineated the analysis of the two collectives: What common processes and products did these successful teacher development collectives possess? Can complexity provide a framework for developing professional learning collectives?

\section{Methodology}

For both of the teacher collectives, participants voluntarily joined these professional learning endeavours. The teacher participants were aware of the fact that they would be working with their peers who had a common goal: to enhance classroom practice. Participants from both of the collectives were homogeneous in that they were all teaching the same subject (science), or providing special education support. Accordingly, the participants possessed an intimate relationship with their subject matter. While all participants from both collectives had similar teaching assignments and positions within their respective school boards, they did not have a pre-existing professional relationship. Hence, there was a degree of vulnerability and risk as they engaged in these collectives. The participants' profiles and actions exemplified the interplay between diversity and redundancy, important conditions for emergence. This 
was exhibited throughout the life of both collectives. The specific issues that the teachers came to discuss and explore within the collectives were open-ended and did not have predetermined outcomes. Instead, in each collective, the participants and the facilitator together determined the foci for each of the gatherings. This dynamic process was captured through the participants' discussions as evidenced below in the descriptions of the two teacher development cases. The techniques used to capture and analyze teachers' oral and written discourses in these collectives are representative of various observational and interpretive methods (Creswell, 2002; Merriam, 1998; Miles \& Huberman, 1994).

\section{Participants, Context, and Data Collection}

The first teacher development case consisted of four middle and secondary school science teachers from four different urban and suburban school boards. These volunteers from a science education Master's level graduate course, were interested in undertaking action research in their science classrooms. The teachers explored ideas and theories related to the teaching and learning of science inquiry and nature of science and critically examined their own practice. From this foundation, the teachers individually designed action research projects to incorporate new or modified curriculum materials and practices into their science classrooms and to better align their practices with key components of scientific literacy. During meetings, their classroom findings were brought back to the group for discussion and critical reflection. Overall, this collective's focus was to implement learning activities for students that better represent contemporary views of science. For the first case, data generated by the four teachers were collected for one academic year while they participated in collaborative activities (bi-weekly meetings). As well, semi-structured participant interviews were conducted with the teachers before and after the teacher collective's activities. All discussions were transcribed, analyzed, and member checked.

For the second case, 15 elementary learning resource teachers from a small, suburban/rural school board formed a collective. As learning resource teachers (LRTs), they provide special education support to students both in withdrawal and integrated class settings. The learning resource teachers came together voluntarily in response to an announcement by the school board superintendent that a resource program was being appraised for use by learning resource teachers. Simply, this program was a synthesis of their assessments and resources and it was designed to guide learning resource teachers to provide focused diagnostic testing and consistent remedial instruction. The resource was developed by the faculty facilitator for the collective. While the primary goal of the resource was to reinforce the assessment-to-intervention cycle, the overarching purpose of disseminating the resource was to enhance and support the practices of elementary learning resource teachers. Over the course of two academic years, the learning resource teachers met bi-monthly to engage in focused discussions on a particular topic in the resource program. The teachers in concert with the facilitator determined the agenda for these meetings and rotated the responsibility of hosting these after-school meetings at their respective schools. During each of the meetings, the facilitator recorded field notes 
and retained samples of the learning resource teachers' work with the program. The resource teachers were surveyed at two points during the study in order to gather insights on how they used the resource program, how they collaborated with classroom teachers, and how they individualized aspects of the program to suit their practice. A sub-group of 4 resource teachers were interviewed after the first year of the study. These interviews were transcribed, analyzed, and member checked.

\section{Data Analysis}

Our objective was to examine the previously collected data from both teacher development cases and determine whether the data provided evidence to substantiate qualities delineated by complexity theory. Through post-hoc analyses of both teacher development collectives, data were appraised for illustrations of three qualities of a complex system: self-organized; bottom-up emergent; ambiguously bounded. In this sense, these qualities were used as benchmarks to judge the organizational structure and operating processes of the collectives and to determine whether the collectives could be attributed as complex systems. We recognize that complex systems' characteristics are interdependent; hence, we understand that it is inappropriate to reduce complexity to a list of qualities (Davis \& Sumara, 2006). However, the goal in our study was to observe these qualities through a post hoc analysis and conceptualize the complex structure and processes found in the two teacher development collectives. We also wished to make these qualities as explicit as possible to the reader; we acknowledge that doing a post hoc analysis was limited due to the scope of the original data. Data were initially reviewed by each of the researchers and categorized for these three qualities, with both the researchers independently verifying each other's categorizations. This careful weaving together of the categories in a collaborative fashion is a form of peer debriefing. Peer debriefing, in addition to prolonged engagement and triangulation of the data, are considered to be rigorous strategies for establishing trustworthiness in qualitative data analysis (Padgett, 1998). As a final point, Miranda, Beisigel, Simmt, Davis, and Sumara's (2006) study of a mathematics teacher development collective utilized a similar method, with the authors collaborating in the analyses of transcripts from their collective.

\section{Self-organization}

Both of the teacher development collectives demonstrated high degrees of functionality as self-organized groups. First of all, as a precept to self-organization, participants from both collectives unified and focused their actions on a common purpose. For the first case, the focus was on scientific literacy goals of scientific inquiry and nature of science, and how teachers can facilitate students' learning of these goals. This necessitated the teachers articulating and reflecting upon their own views of these goals, and then discussing how they would assist students in their own classroom to construct their knowledge and understandings. For the second case, each learning resource teacher was provided with a copy of the resource program; their focus was to become familiar with the resource and implement it in their own practice. The learning resource teachers came 
together to share their insights from the field. They discussed how the resource program streamlined their responsibilities and helped them to provide efficient access to a variety of assessments, interventions, and supports.

An integral characteristic of a functional, self-organized collective is the tension between the individual and the collective-this provides a trigger for emergence. For instance, each member of the group valued the conceptual inputs and reflection offered by each of the other members of the teacher development collective. During meeting discussions, teachers in both cases respectfully took turns sharing stories about their practice and openly disclosing their challenges:

The action research project allowed problem-solving opportunities and discussions that were very helpful. The mere fact of being part of a collaborative group kept the project focused. The ideas and stories that others shared, even if it wasn't directly associated with my action project, influenced the direction of my project. The sharing of research and literature had untold value in the entire process. (Alicia, post-project interview, Science teacher collective)

We had permission to make mistakes [administering assessments] at the beginning...Then we brought back some student profiles [to the meetings] and you know, someone might say, "Here is what you found on this screen, what are you going to do with this student?" And we worked through it a couple of times. (LRT \#4 interview, Learning resource teacher collective).

One of the final tasks that the Learning resource teachers decided to do is a case study of one student that they find particularly challenging to work with. Each teacher used the resource program to assess, program for and instruct a student. The Learning resource teachers prepared a summary of their case study and shared this at our meeting. Colleagues were encouraged to comment on the case and offer suggestions. They loved this culminating task of application. (Facilitator, Fieldnotes, Learning resource teacher collective).

One of the learning resource teachers who has extensively used the program asked her colleagues what their greatest frustration was in their position as learning resource teacher. Candidly, all of the teachers present started to share intimate issues of angst such as a lack of communication with staff, too many responsibilities to deliver an action plan based on the IEPs, and creating IEPs that aren't followed (Facilitator, Fieldnotes, Learning resource teacher collective)

In addition, the teachers participating in the collectives had significant expertise (e.g., specialty degrees in the discipline; additional qualifications in science or special education) in their respective domains (i.e., science education; special education), yet were diverse with respect to their roles and relationships as teachers within their individual schools. For instance, in the science teacher collective, all the teachers came from different school boards and were responsible for different science subjects and grade levels. In the learning resource teacher collective, even though the teachers came from the same school board, their individual schools had different demographic characteristics and they had disparate student caseloads. 
Overall, the diversity found in each teacher development collective enhanced discussions and reflection during collaborative sessions. This sharing of expertise was critical as the participants disclosed and entered into productive and critically reflective dialogue regarding teaching strategies, and differing institutional challenges to implement newly developed teaching strategies - these discussions might not have occurred if the participants had been in very homogenous or stable collectives evidence of a collective product from the emergence. Below are some excerpts from participants' interviews expressing this diversity condition:

I really liked the process, and the form of getting together in collaborative action research. To hear the range of experiences...how everyone else was doing. Initially, I felt like I needed to work a little harder considering what others were doing but it forced you to stay on task. It was great, a great experience. (Luke, post-project interview, Science teacher collective)

Being part of this group really helped me because I had the emotional support. The right people were in our group because they all wanted to do this kind of stuff. These were my peers, who had the same expertise, but their own spin on things. And we all respect that. (LRT \#2 interview, Learning resource teacher collective).

Participants continuously exchanged their personal teaching experiences and perspectives. This exchange was unprompted, and at times, unanticipated. Even though the teachers within each collective had the same professional responsibilities, they offered unique perspectives based on their personal backgrounds and teaching assignments. Collectively, new insights emerged that went beyond the individuals' experiences.

Like other researchers using a complexity framework (e.g., Davis \& Sumara, 2006; Davis \& Simmt, 2003; Miranda et al., 2006) we were challenged to find evidence of this seminal quality within our collective, yet we knew intuitively that it had existed. Specifically, the diverse and interactive conditions present in these collectives allowed the teachers to develop in personal and professional ways. Consider the following remarks from participants at the conclusion of the collectives:

Well for me, I saw individuals doing their own thing and yet we could help each other. I definitely benefited from the discussion that you facilitated and your input into my approaches to things. (George, collaborative meeting, Science teacher collective)

In the beginning you [the facilitator] were much more assertive in terms of us focusing on an area, the curriculum; and, as it progressed it got more into what we were doing. I think it was good to start there because I didn't even think about the provincial curriculum or the nature of science from an action research point of view. (Alicia, collaborative meeting, Science teacher collective)

My thinking, it has changed. It has crystallized some of my thinking and clarified some of my thinking. And that informs my program delivery and development...Now, I really break down the skills and make sure that I am teaching the sub-skills. I am more clear about noticing who [the student] is weaker at one sub skill then another. (LRT \#2, interview, Learning resource teacher collective) 
I am thankful to have the resource and activity correlations to refer to [in the resource program]. Even if I didn't have a particular resource book, I was able to substitute it with my own idea or other materials. It was a good place to start. (LRT \#5, survey, Learning resource teacher collective)

These excerpts from participants weave together a tapestry of discourse illustrating the nature of the self-organized experience, and allude to what conditions (e.g., internal diversity and redundancy) need to be in place in order for self-organization to occur.

\section{Bottom-up emergent}

Once organized, these two teacher development collectives materialized as bottom-up emergent groups This quality is complementary to self-organization in that a complex collective exists without a predictive control agent, and emergent events can arise. For instance, in the science teacher collective, without prompting from others or the facilitator, there was a continuous sharing of resources by all members during meetings. This was indicative of the shift of locus of control away from the facilitator to the group. In addition, the trust and growing intelligent capabilities of individuals in the collective to raise contentious science curriculum issues and collaboratively reflect upon them was descriptive of the decentralization. Overall, as two respective collectives, the cases clearly were comprised of individual teachers each with their own set of dispositions and experiences; however, these individuals coagulated to form a dynamic learning system that was neither directed nor expected from the facilitators of the groups. Both of the collectives existed without dependency of official school board personnel or other governing structures. Furthermore, the teacher development collectives met during their own time with their facilitators. This set a trusting tone of candidness for the group meetings. The "bootstrapping" phenomenon occurred soon after the initiation of the collectives:

Although I [the facilitator] assumed the chair for the first few collaborative meetings, by the end of fourth collaborative meeting, I joined the group and became a participant...all teachers seemed to focus and deeply reflect on the "habits of mind" concept found in the front matter of the science curriculum, and they are becoming more critical of the provincial curriculum.....I was glad Alicia brought handouts to share. It was very useful to the discussions and I think we are beginning to switch from a cooperative and practical-oriented group to a more participatory group, i.e. sharing and critiquing. (Facilitator, Journal entry, Science teacher collective)

The learning resource teachers appreciate debriefing sessions and opportunities to share best practices with their colleagues. There were several suggestions that future meetings should continue with the existing members taking a leadership role. (Facilitator, Fieldnotes, Learning resource teacher collective).

Facilitator: What has to happen now is someone to take some leadership during each session - this will not be my role.

Learning Resource Teacher \#2: No. 
Facilitator: I'm hoping that each one of the resource teachers tries that role.

Learning Resource Teacher \#2: Awesome!

Facilitator: So we will have someone who chairs the meeting and gets things going.

Learning Resource Teacher \#2: And says that this is what we're doing today, we're going to talk about this one thing.

Facilitator: We are all professionals and we can pull together that way.

The bottom up characteristic of the collectives supported unique yet unpredictable developmental events, illustrating the emergent behaviour of the collectives. For example, in the learning resource teacher collective, a few sub-groups of learning resource teachers began to meet on a bi-weekly basis on their own accord. They referred to these as "splinter groups" and one teacher commented that, "Our splinter groups were really helpful to share resources and rich discussion." (Learning resource teacher \#13, survey, Learning resource teacher collective). These teachers were from neighbouring schools and found it convenient and beneficial to meet on a more frequent basis to share assessments and materials.

Once initiated, a central facilitator was not required to sustain the teacher learning collectives; however, a facilitator was still present to support, provide expertise, and mediate the collectives' discussions. This seminal step is important to recognize for other individuals interested in organizing complex system collectives.

\section{Ambiguously bounded}

Each of the collectives demonstrated an ambiguously bounded characteristic in both structure and process. With respect to structure, there was a lack of distinction amongst the levels of organization that the collectives were embedded in. Indeed, each collective was a subset of larger structures (i.e., schools and school boards) and they interacted, accordingly, in complex ways. All the teachers participating in both collectives were professionally bound to different schools, yet participating voluntarily in these collectives. This created a fuzzy boundary between the schools and the teacher collectives as the teachers were not necessarily familiar with each other or their local context of practice. Nevertheless, there was a distinct social structure to each collectivea pattern of relationships amongst the teachers and the facilitators which can be described as dynamic, yet organizationally closed. This was initiated through specific engagement by each teacher within their respective collective (e.g., expertise in the domain; voluntary participation) and the defining of specific roles and routines (e.g., sharing of resources; facilitator-initiated discussion) allowing the collectives to capably function.

With respect to the functions of the collectives, the interactions within them were dynamic as the participants were engaged in open discussions. Group dialogue, reflection, and professional activities were candid and fluid. This exchange was driven by the participants' needs for more information and deeper understandings with respect to a particular topic. In this fashion, the collectives were constantly exchanging 
knowledge. Individual participants frequently came forward to lead discussions based on their comfort with a given topic. To illustrate, in the science teacher collective, the teachers clarified the curricular definitions of science inquiry and nature of science, addressed the developmental and disciplinary coherence of said definitions, and related these concepts to the authentic practices of scientists and engineers. In the learning resource teacher collective, there were meetings focused on a specific screening device, a phonemic awareness resource manual, or a method of tracking student assessment data.

As well, discussion topics ranged beyond those that were predictable and, on the surface, appeared to be tangential. For instance, in the science teacher collective, during their collaborative discussion, the teachers explored how an important scientific literacy goal for students, understanding the nature of science, was not sufficiently represented in the provincial curricular structures, and they speculated why this was the case. Below are some excerpts from a collaborative meeting discussion that occurred half way through the collective's duration. This excerpt illustrates how the teachers theorized about the lack of explicit nature of science learning expectations in the science curriculum:

It's just a part of so many other factors that it gets put to the wayside. So you can't explore nature of science because the curriculum document requires straight content. (Alicia, collaborative meeting, Science teacher collective)

How many of you studied NOS during their undergraduate education? (Facilitator, collaborative meeting, Science teacher collective)

You're not taught nature of science. You're taught " $x, y, z$ " and at the end of the day you have an idea of what science is to you, so why should they teach you that? You've already formed your understanding of what science is. You've never been asked to question it. (George, collaborative meeting, Science teacher collective)

Scientists don't talk about the nature of science because they live within it. They are surrounded by it always and may not even be conscious of it. As a graduate student in Botany, I learned about what counts or doesn't count from my supervisor, not from a text...It is assumed that you picked up nature of science ideas somewhere along the line. But kids don't know this...I think this is a mistake and it's dangerous to society. (James, collaborative meeting, Science teacher collective)

Do you think students are just "picking-up" nature of science concepts when they do experiments in science class and so on? (Facilitator, collaborative meeting, Science teacher collective)

Over the years you pick up something about nature of science, but you've never been asked to articulate it, but you do have an understanding of it by what you do in class and by the media. I think it should be discussed throughout the entire science curriculum. But it doesn't surprise me that these curriculum documents don't have any of it. (George, collaborative meeting, Science teacher collective)

I think it should be there precisely because without it we give a false view of what science involves. (James, collaborative meeting, Science teacher collective) 
I look at the students that I teach and they're very similar to the way I taught in school. And I fall into the same traps now that my teachers fell into when I was a student. We need to challenge ourselves to go in a new direction and get away from the old methods. We have to take them a step forward to abandon the status quo. (George, collaborative meeting, Science teacher collective)

In a similar fashion, the learning resource teachers extended their discussions around how to transfer their understandings into the mainstream classroom contexts. Specifically, some of the dialogue speculated on how the learning resource teachers could support students' learning in their regular classroom settings. This necessitated a plan for exchanging information and resources with the classroom teachers in the school-at times this is not easily facilitated:

The resource program can help to educate teachers on skills that they [mainstream classroom teachers] need to be monitoring. It provides a common language for discussing students with needs. (LRT \#9, survey, Learning resource teacher collective)

I assessed students in Sept/Oct. using the screens. Then I met with [mainstream] teachers and discussed re-occurring weak literacy skills within their groups of students. We discussed their assessment and observation results and my assessment results. Then, I planned a sequenced program starting at the instructional level for each group. I choose activities from resource program that would address these weaknesses. (LRT \#12, survey, Learning resource teacher collective)

While each collective had an initial purpose and thus was bounded, the topics were not fixed over time; rather, the topics were recursive and extending as the collectives progressed over time, having a non-linear and unpredictable quality.

We have presented data excerpts from two teacher development collectives from which significant professional learning outcomes emerged. The evidence presented suggests the plausibility of recognizable tenets of complexity theory within these teacher development collectives. Both collectives exhibited structural and functional qualities that can be ascribed to complexity theory (i.e., self-organized; bottom-up emergent; ambiguously bounded). More importantly, these descriptions from the collectives provide empirical substantiation and practical application for complexity theory within an educational context. We recognize that complexity is only one lens to analyze the collectives' structures and dynamics. Nevertheless, we believe that complexity provides a meaningful framework to do so. From these findings, we discuss the implications of complexity theory and teacher development, and allude to its application. In the final section, we proceed to present a diagrammatic representation that attempts to capture the initiation, development, and outcomes of teacher development collectives.

\section{Discussion and Implications}

Examination of these two seemingly disparate teacher development collectives using a complexity framework has produced an intimate discussion of professional learning, science education and special education instruction. The two teacher development 
collectives displayed many of the qualities of complexity and, as such, have provided evidence of the robustness of complexity theory for educational phenomena. Initially, we embarked on this examination using the qualities of complexity theory as the criteria through which we filtered our pre-existing findings. In other words, the characteristics that supported learning within these two productive collectives were already present, but not yet identified. Other studies of teacher development have also followed a similar path.

For instance, a study by Zellermayer and Margolin (2005) described how a transformational experience of learning in a professional community of student supervisors within a teacher education program could be examined through the lens of complexity theory. Similar to our study, Zellermayer and Margolin used complexity theory in a post-hoc manner, returned to their data and experiences as facilitators, and were better able to describe the dynamic transitions they witnessed in the collective. The tenets of complexity theory provided them with new descriptors and metaphors, which enabled them to legitimately re-examine the transformational experiences they witnessed and participated in. Like our study, this helps to support the plausibility of complexity theory when examining teacher development.

In addition, a study of collectivity and mathematical learning by Miranda et al., (2006) also demonstrated how complexity theory can provide a framework to analyze a research project about a teacher development program. Their study of eight mathematics teachers revealed how a collective consciousness emerged (self-organized) from the interactions amongst the teachers and facilitators in their collective, and their intimacy with mathematical knowledge. This self-organized quality found in their mathematical teacher collective corresponds with the findings from our teacher collectives, and suggests that if specific conditions within a collective are prompted, then a complex teacher development system may be induced.

These conditions, however, are not new to successful teacher development experiences. A large scale study of the development of teachers (Garet, Porter, Desimone, Birman, \& Yoon, 2001) revealed the following conditions for effective professional development: sustained and intensive learning activities, subject matter foci, active learning opportunities, school context integration, and collaborative group interactions. Their study revealed that together, these professional development conditions were more likely to produce enhanced teacher knowledge and skills. These conditions for high quality teacher professional development, which included sustained and focused teacher groups, align with qualities that were found in our teacher collectives. A distinct feature of our work, as compared to Garet et al. (2001), centred on internal diversity. Our collectives were enhanced because of their individual contexts and antecedent personal attributes of the teachers. Garet et al.'s study does not recognize this feature in their sample. As such, having a complexity framework could have extended their research findings, recognizing the importance of internal diversity in teacher development.

With this in mind, a natural extension of our findings would be a recommendation to teacher development facilitators to use complexity theory in the design and 
implementation of their projects. Complexity theory offers tools and language to describe these types of teacher development conditions and gives plausibility for its discussion and application. To assist with this, we provide a diagrammatic representation (see Figure 1) that illustrates some of the inherent qualities and descriptive conditions of complexity in our teacher development collectives. We developed this representation inductively as we applied complexity theory to analyze these professional development collectives. Moreover, we recognize that this is only a hypothetical tool that requires further deductive investigation. Below we will describe the components and dynamics of the schematic in order to better illustrate complexity thinking and professional development collectives.

During the planning phase of a teacher development collective, it is essential to acknowledge that a mandatory pre-requisite is a focus for the teacher development initiation. The emergence of a teacher development collective should be marked by an initial gathering where the members come together and become familiar with each other, the facilitator, and their common objectives. Members of the teacher development collective should leave this initial gathering with an apparent sense of intention for the teacher development experience. Accomplishing this goal exemplifies the self-organized quality of a complex system since self-organization is the emergence and union of a group around a clear purpose (Davis \& Sumara, 2006). This first meeting is important to establish a bond within the communal group such that members will be able to identify with each other and their shared goals to enhance their practice in some fashion. This is an integral task for the skilled facilitator of a teacher development collective, as it is instrumental in rallying the direction for the sustainability of the collectives.

Subsequently, individual teachers will have their first opportunity to begin independent inquiry as they engage with the professional development topics and begin to prune or personalize the topics for their educational contexts. Once personalized (e.g., a teacher can contextualize a novel topic/practice in their classroom), the teacher may then apply in the classroom these topics and ideas. The small recursive loops (i.e., independent inquiries) represent each individual participant's engagement in personal knowledge building within their own contexts. The effect or impact on practice should be interpreted by each teacher and then a process of self-assessment needs to take place. Independent inquiry is likely to be reiterative as the teacher re-engages with certain topics or explores new ones, building from past learning. Ultimately, the teacher emerges from this inquiry with an enhanced sense of self-efficacy as an educator because of the newly constructed personal knowledge, which then can be capably applied into practice. It is obvious that outcomes are dependent on the independent actions of each of the teachers and accordingly, the collective can develop with a bottom-up emergence quality (Davis \& Sumara, 2006). During independent inquiry, the role of the facilitator is similar to a consultant in that the facilitator may be called upon to provide clarification or support to any one given teacher. 


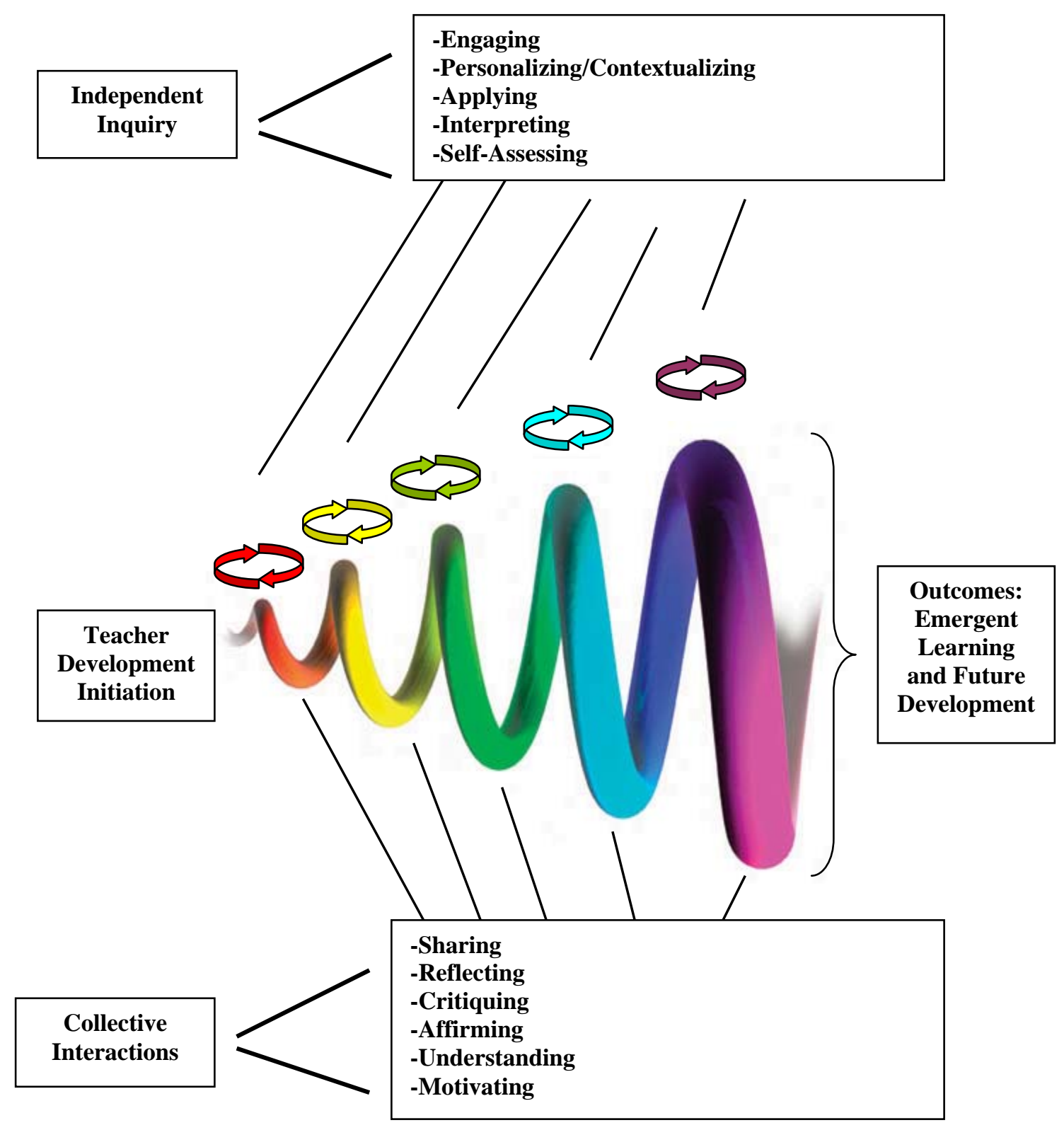

Figure 1: Diagrammatic Representation of a Teacher Development Collective

Discussion then re-commences as the teacher development collective reconvenes as a group for collective interactions. With the facilitator of the teacher development collective present, individual members take turns sharing their anecdotes, sharing resources, reflecting on their experiences and being available for each other beyond the parameters of the meetings. Collegial critiquing should occur in which members evaluate and comment on their colleagues' practices. This type of evaluative peer 
feedback can be affirming for an individual teacher who requires assurance and support. In this fashion, the collective's interactions foster individual members' deeper understandings of the professional development topics and promote motivated, purposeful continued activities through independent inquiry. Continuance of these collective interactions, exemplifies the ambiguously bounded quality of dynamic complex systems as individuals within the collective exchange information as part of an intricate network (Davis \& Sumara, 2006).

In a recursive fashion, the independent inquiry feeds back into collective interaction cycles, which can continue for several rounds. With each successive round, the interactions within the teacher development collective become more involved and the identities of the individual teachers become further defined. The quality of the interactions is integral to the recursive and enhanced development of the collective. The facilitator of the teacher development collective ensures that this momentum is maintained, but does not interfere with the emergent experience. There is a temporal completion of the collective's activities; however, the individual members will carry on with independent inquiry, continuing to generate other emergent learning opportunities and future development. This is more substantive than if they pursued these independent activities alone. The facilitator may maintain informal contact with the individual teachers and continue to assess and evaluate the outcomes of the learning from the teacher development collective.

With respect to outcomes, as a group, the teachers within each of the collectives highlighted here achieved emergent learning (e.g., teacher resource artefacts) that influenced their professional practice. The teachers in both collectives overwhelmingly attributed this learning, both in structure and process, to the dialectical relationship between the individual and the group. It is important to recognize that learning was achieved individually and collectively, but cannot be reduced because of the complex nature of these collectives.

We have offered a diagrammatic representation as a model to consider when developing and enabling complex collectives in their contexts. Structurally speaking, the components of a teacher development collective (teacher development initiation, independent inquiry, collective interactions) need to be present before the active processes (e.g., engaging, applying, interpreting, self-assessing, critiquing) may begin. The role of the facilitator is key to promoting the qualities of complex systems (e.g., selforganized; bottom-up emergent; ambiguously bounded). This integral role should be recognized at the inception of the teacher development collective, during the functioning activities of the collective and when analyzing the teacher development collective's outcomes.

To summarize, our post hoc analysis enlarges a learning space for both ourselves and hopefully our readership as a way to structure teacher development collectives from their inception. We believe the robustness of complexity theory and its applicability to analyzing teacher development collectives has much to contribute for teacher development facilitators and researchers who are seeking to support and study professional learning experiences. The qualities and conditions promoting teacher 
development are essential aspects of professional learning; however, they can easily become disparate lines of inquiry causing theoretical reductionism by educational researchers. As well, this can contribute to piecemeal design and implementation by teacher development providers. We believe that complexity theory can provide a framework for planning, facilitating, and researching of teacher development collectives.

\section{Acknowledgments}

A version of this paper was presented for the Canadian Association for Teacher Education (CATE) at the Annual Conference of the Canadian Society for the Study of Education (CSSE), University of British Columbia in May 30-June 3, 2008.

\section{References}

Bar-Yam, Y. 2004. Making things work. Solving complex problems in a complex world. Cambridge, MA: NECSI Knowledge Press.

Bell, B., and J.K. Gilbert. 1996. Teacher development: a model for science education. London, UK: Falmer Press

Creswell, J. W. 2002. Educational research: Planning, conducting, and evaluating quantitative and qualitative research. Columbus, $\mathrm{OH}$ : Merrill, Prentice, Hall.

Davis, B. 2004. Inventions of teaching: a genealogy. Mahweh, New Jersey. Lawrence Erlbaum

Davis, B., D. Sumara, and R. Luce-Kapler. 2008. Engaging minds: Changing teaching in complex times (2nd $E d$.). New York: Taylor and Francis.

Davis, B., and D. Sumara. 2006. Complexity and education: Inquiries into learning, teaching, and research. Mahweh, New Jersey: Lawrence Erlbaum Associates.

Davis, B., and E. Simmt. 2003. Understanding learning systems: mathematics teaching and complexity science. Journal for Research in Mathematics Education 34 (2): 137-167.

Doll, W.E.J. 1993. A post-modern perspective on curriculum. New York: Teachers College Press.

Fullan, M. 2007. Change the terms for teacher learning. Journal of Staff Development 28 (3): 35-36.

Garet, M.S., A.C. Porter, L. Desimone, B.F. Birman, and K.S. Yoon. 2001. What makes professional development effective? Results from a national sample of teachers. American Educational Research Journal 38 (4): 915-945.

Hoban, G. F. 2002. TeacherlLearning for educational change: A systems thinking approach. Buckingham, UK: Open University Press.

Holland, J. H. 1995. Hidden order: How adaptation build complexity. New York: Helix Books, Addison Wesley.

Loucks-Horsley, S., N. Love, K. Stiles, S. Mundry, and P.W. Hewson. 2003. Designing professional development for teachers of science and mathematics. Thousand Oaks, CA: Sage Publications.

Miles, M. B., and M. Huberman. 1994. Qualitative data analysis: An expanded sourcebook (2nd Ed.). Thousand Oaks, California: Sage Publications Inc.

Miranda, H., M. Beisigel, E. Simmt, B. Davis, and D. Sumara. 2006. Conciousness, collectivity and culture: Experiences of intimacy in mathematics learning. Journal of the Canadian Association for Curriculum Studies 4 (2): 123-137.

Merriam, S.B. 1998. Qualitative research and case study applications in education. Jossey-Bass Publisher, San Francisco: CA.

Padgett, D.K. 1998. Qualitative methods in social work research: Challenges and rewards. Thousand Oaks, CA: Sage.

Paley, J. (2007). Complex adaptive systems and nursing. Nursing Inquiry 14 (3): 233-242.

Phelps, R. 2005. The potential of reflective journals in studying complexity 'in action'. Complicity: An International Journal of Complexity and Education 2 (1): 37-54. 
Volk, T., and J.W. Bloom. 2007. The use of metapatterns for research into complex systems of teaching, learning, and schooling Part I: Metapatterns in nature and culture. Complicity: An International Journal of Complexity and Education 4 (1): 25-43.

Yoon, S., and E. Klopfer. 2006. Feedback (F) fueling adaptation (A) network growth $(N)$ and self-organization (S): A complex systems design and evaluation approach to professional development. Paper presented at the Annual Meeting of the American Educational Research Association, San Francisco, April 2006.

Zellermayer, M., and I. Margolin. 2005. Teacher educators' professional learning described through the lens of complexity theory. Teachers College Record 107 (6): 1275-1304. http://www.tcrecord.org, ID Number: 11911.

\begin{abstract}
About the Authors
Xavier Fazio is a member in the Teacher Education Department of the Faculty of Education at Brock University. As a science educator, he teaches secondary science teaching education and professional practices and certification for teachers. Xavier's current research interests include science and environmental literacy, teacher development, assessment literacy, and complexity theory in educational contexts. Xavier may be reached at: xavier.fazio@brocku.ca
\end{abstract}

Tiffany L. Gallagher is also member in the Teacher Education Department of the Faculty of Education at Brock University. She teaches courses in educational psychology and assessment and evaluation. Tiffany's current research interests include literacy assessment; reading and writing strategy instruction; the role of the special education teacher; teachers with learning disabilities; post-secondary education for persons with disabilities, and complexity theory in educational contexts. Tiffany's website is http://www.ed.brocku.ca/ tgallagh/ and she can be reached at: tiffany.gallagher@brocku.ca.

(C) Copyright 2009. The authors, XAVIER FAZIO and TIFFANY L. GALLAGHER assign to the University of Alberta and other educational and non-profit institutions a non-exclusive license to use this document for personal use and in courses of instruction provided that the article is used in full and this copyright statement is reproduced. The authors also grant a non-exclusive license to the University of Alberta to publish this document in full on the World Wide Web, and for the document to be published on mirrors on the World Wide Web. Any other usage is prohibited without the express permission of the authors. 